\title{
VOCABULARY ACQUISITION
}

\author{
Marioara PATEŞAN*, Alina BALAGIU**, Dana ZECHIA** \\ *"Nicolae Bălcescu" Land Forces Academy, Sibiu, Romania \\ ***Mircea cel Bătrân" Naval Academy, Constanța, Romania \\ mpatesan@yahoo.com, alinabalagiu@yahoo.com,dzechia@yahoo.com
}

\begin{abstract}
Introducing vocabulary to students is not always an easy task. Due to music and movies that young people are exposed to today, vocabulary acquisition is more often not taken seriously. Young people can hum or repeat sentences from a movie that impress them and think that they are able to communicate in a foreign language. In an academic environment you realize that each new vocabulary word is like a brick needed to build up a whole wall; is a small step that help you enrich your abilities to speak, write and understand all the English you might need at a certain time in your professional life. Studies have shown that the more words you know in a foreign language the more you can use it in real life situations. In this study we will approach the theoretical studies related to vocabulary acquisition as well as some practical exercises that might be used in class.
\end{abstract}

Keywords: vocabulary development, meaning, lexical patterning, communication.

\section{Introduction}

Enriching vocabulary is a very important issue in the teaching learning process. You cannot communicate well if your vocabulary is limited. Our students should be given as many opportunities to use the words they have learnt in practicing speaking, writing or reading comprehension. Communication is not a long list of words but intelligible sentences and phrases, collocations and expressions and idioms the native speakers use in everyday situations. To reach fluency in a foreign language is a difficult process implying hard work and lots of practice. But what is vocabulary after all? In trying to answer this question we will find the answer in an Oxford dictionary and the work of Lessard-Clouston. According to Oxford Advanced Learner's Dictionary [1] vocabulary is "the body of words used in a particular language" while LessardClouston, defines it as "words of a language, including single items and phrases or chunks of several words which convey a particular meaning, the way individual words do".[2] In other words, it is all the words and chunks of words that help an individual understand the meaning/s encountered in speech or writing or help $\mathrm{him} /$ her produce language.

\section{Related literature}

Over the years linguists debated over the primary role of grammar over vocabulary. Wilkins stated that "without grammar very little can be conveyed without vocabulary nothing can be conveyed" [3] while Wallace considered that "to communicate with other people we should use appropriate vocabulary or our communication will stop"[4]. McCarthy affirms that "No matter how well the student learns grammar, no matter how successfully the sounds of L2 are mastered, without words to express a wide range of 
meanings, communication in an L2 just cannot happen in any meaningful way"[5]. Vocabulary should be recognized as a central element in language teaching.

When it comes to the English language experts consider it has the "largest vocabulary in the world" [6]. Educated native speakers of English are supposed to know approximately " 20,000 -word families or 70,000 words" [7]. Educated non-native speakers of English know less than one quarter of the native speakers' vocabulary [8]. Thus, if we agree with these statistics, we realize that ESL students must increase their vocabulary if they want to become good practitioners of the language. According to R. Carter \&Mc Carthy there are three conditions so as learners could say they know a word: "lexical patterning"which words it is usually associated with; "grammatical pattering" -what grammatical characteristics it has; their "pronunciation and spelling" [9], while some other experts think of words as

"known/ unknown" [10] and not in "levels of understanding" [11].

In the study Overcoming Learning Difficulties (2010) published in Reading \& Writing Quarterly the authors discuss the close relationship between vocabulary development and reading comprehension. that stress the fact that "teachers must maximize opportunities for text reading, vocabulary building, and improving comprehension in the core content areas in which text with varying structures and purposes for learning may be utilized"[12]. Vocabulary acquisition has been studied by many language experts and professionals, all of them coming up with different theories and ideas of putting them in practice. All of them have agreed that a rich vocabulary in a foreign language leads to proficiency as the lack of vocabulary knowledge often has a "more severe impact on clarity and fluency of spoken and written language than insufficient grammatical knowledge or poor pronunciation"[13].
The question: What is so difficult about knowing a word? was answered by Batia Laufer who speaks of five categories: Form- "knowing its spoken forms, being able to recognize it in writing or print and spell it correctly." Then comes the word structure-"detecting the correct meaning of a word by" knowing roots and affixes" which is not an easy task as it may lead to false interpretation; followed by syntactic behaviour of words- when it comes to errors in trying to "translate" the foreign word in your mother tongue; meaning, which includes the "referential meaning (homonyms, polysemes, idioms etc.) affective meaning, and the pragmatic meaning and lexical relations related to "synonymy, antonyms as well as its collocations." The author comes to the conclusion that "these five categories are related to different pitfalls that a learner might encounter, either due to L1 transfer or from misconceptions of words and their different meanings and connotations"[14].

Vocabulary learning becomes "most effective when the learners' proficiency level is advanced" as they know when and how to use "contextual clues and be aware of word families and affixes for analysing words" [15]. Daneman argued that "the development of a large and varied vocabulary is a critical educational task" and he was so right in this regard [15].

\section{Types of exercises}

What are the best ways to teach vocabulary? is a question that each and every foreign language teacher asks so often during the teaching process. It is easy to theorize over the known techniques such as the importance of teaching vocabulary in context, combining vocabulary with reading and writing activities, and giving the students enough lexical information about the words to be studied, but to put them in practice is another issue. Most teachers agree with what Nation stated that "teaching vocabulary should not only consist of teaching specific words but also 
aims at equipping learners with strategies necessary to expand their vocabulary knowledge"[17]. So, the first lesson about vocabulary should be: Teach \learn vocabulary in context! Words memorized from a list will be a waste of time. How can your student grasp the meanings of let's say the word branch if you do not introduce it in different contexts such as:

How many branches of $\mathrm{X}$ bank are there in your town?

The branches of the apple tree are heavy with ripe apples.

The soldier's branch is artillery.
It is very important that the language surrounding the context is easy to understand as you are interested in the target vocabulary We should remember what Stahl (2005) said: "Vocabulary knowledge is knowledge; the knowledge of a word not only implies a definition, but also implies how that word fits into the world"[18]. We will introduce some of the ways we use in class to enhance the students 'vocabulary.

1. Use visuals-using clip art or pictures to illustrate certain words.

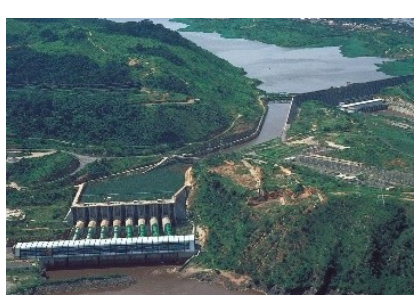

dam

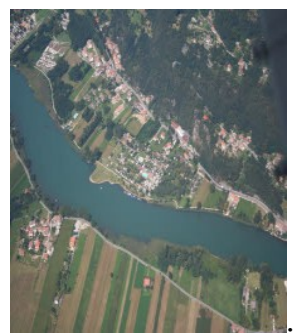

river

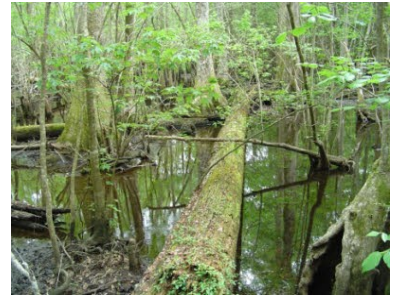

swamp

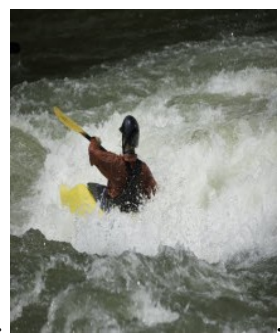

rapids

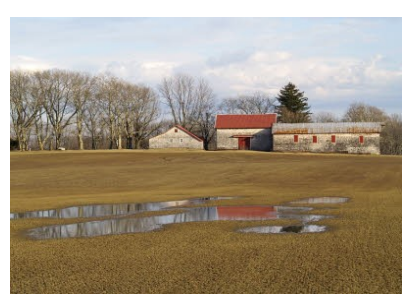

puddle

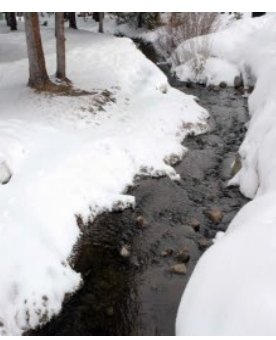

stream / brook / creek
2. Matching. If the lesson is about Vacations you can ask the students to match the words with their definitions selecting words like: culture (The habits, traditions and beliefs of a group of people.) cancel (To decide that an organized event will not happen.); sightseeing (The activity of visiting places which are interesting); tourist (Someone who visits a place for pleasure and does not live there.); accommodation (The place where you stay.) guide (A book that gives information about the place you are visiting.); luggage (Bags and cases that you carry with you when you are travelling.); terminal (A building where you can get onto an aircraft, bus, or ship.); coach (A comfortable bus used to take groups of people on journeys); sunbathe (To sit or lie in the sun so that your skin becomes brown.); rent (To pay to use something for a short time.) or you can prepare a crossword as suggested by Vocabulary Games and Activities at https://www.cambridgeenglish.org/images/ vocabulary-games-and-activities.pdf

3. Fill in the blanks. We can use lyrics of well-known songs for this activity. The missing words can be placed in a box adding some extra words and ask the students to fill in the blanks. An example 
used for this activity is the song Granted performed by Josh Groban to practice verbs. The students can listen to the song first and the fill in, but if they are advanced students first they should fill in and then listen to the song and check their choice of words.

\begin{tabular}{|c|}
\hline \multicolumn{2}{|c|}{ wonder chase falls running } \\
blink felt waste take counted \\
embrace bet listen
\end{tabular}

"Have you ever felt it could all go away If you blink

If you never stop running you won't fall behind

So you think

And you wonderin your heart
If you're still not who you are

Who are you?

Nothing's as it seems till it all falls apart

If you have a dream, go ehase it

If you feel hope, don't waste it

If you find love, embrace it

And never a single breath for granted...

Our days are eounted on this planet...

Maybe it's time you bet on yourself

Eisten to your heart"

4. Find the word that fits the number. You can use a picture and number the words you want your students to learn. For example, you can ask them to describe a fighting order by following the numbers.

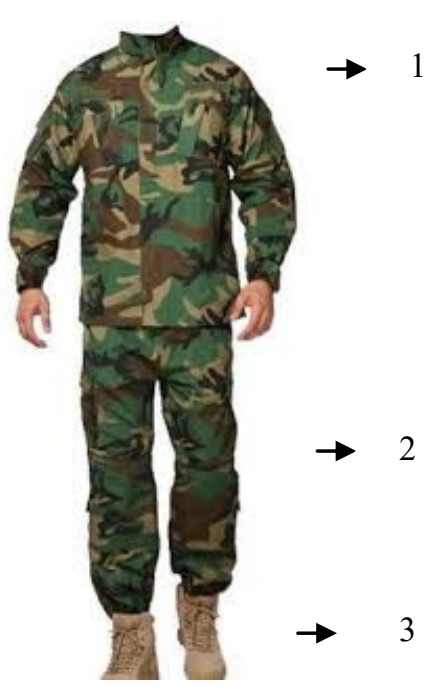

No matter what types of exercises we use in class there is only one goal: to help the students enrich their vocabulary. There are many more other ways to practice vocabulary such as synonyms $\backslash$ antonyms usage, collocations or words often confused or organising a personal dictionary on certain topics, a binder or index cards.

\section{Conclusions}

We can conclude by saying that a foreign teacher has to use selected vocabulary activities in class taking into consideration the students' level of proficiency. Teachers should teach vocabulary in a well planned way and on a regular basis if they want their students' vocabulary enhancement. From guided discovery of new words, making use of the context to guess the word to learner's independent work with dictionaries and other resources, all techniques can be used. The materials used should be authentic so that the students are exposed to rich, contextualised language to be able to acquire the vocabulary needed to comprehend the content and information they might come across in their daily activities. Teachers should guide their students to find the appropriate strategies that help them enhance their vocabulary and practice it in situational contexts. 


\section{References}

[1] *** Oxford Advanced Learner's Dictionary (2012)

[2] Lessard- Clouston, M.;(2013) Teaching Vocabulary. TESOL International Association

[3] Wilkins D. A.; (1974) Linguistics in Language Teaching, London, Billing and sons Ltd, p 43

[4] Wallace, M. J.; (1982), Teaching vocabulary, London, Heinemann Educational Books Ltd, p 9

[5] McCarthy, M.; (1990).Vocabulary, Oxford: Oxford University Press

[6] Crystal, D.; (2002). The English language, London: Penguin;

[7] Nation, P.; (2001) Learning vocabulary in another language, Cambridge, UK: Cambridge University Press;

[8] Laufer, B., \& Yano, Y.; (2001). Understanding unfamiliar words in a text: Do L2 learners understand how much they don't understand? Reading in a Foreign Language, 13, 539-566.

[9] Carter, R., and McCarthy, M. (Eds).; (1988). Vocabulary and language teaching, New York: Longman

[10] Laufer, B., \& Nation, P.; (1999). A Vocabulary-Size Test of Controlled Productive Ability, Language Testing, 16, pp. 33-51.

[11] Schmitt, N.; (1998) Tracking the incremental acquisition of second language vocabulary: Longitudinal study. Language Learning 48.2, pp. 281-317

[12] Swanson, Elizabeth \& al; (2010) Overcoming Learning Difficulties published in Reading \& Writing Quarterly, p 21

[13] Hedge, Tricia, (2002). Teaching and Learning in the Language Classroom, Oxford, Oxford University Press, p. 86, https://www.amazon.com/Teaching-LearningLanguage-Classroom-Handbooks/

[14] Laufer, B.; (1991) Knowing a word: what is so difficult about it? English Teachers' Journal, no 42 pp. 82-85, https://www.researchgate.net/publication

[15] Folse, K.; (2004).Vocabulary Myths: Applying Second Language Research to Classroom Teaching, University of Michigan Press, p.67

[16] Daneman, M.; (1991) Working Memory as a Predictor of Verbal Fluency, Journal of Psycholinguistic Research, 20, p. 445.

[17] Nation, P.; (2001), Learning vocabulary in another language, Cambridge, Cambridge University Press, p. 223

[18] Stahl, S.A.; (2005). Four problems with teaching word meanings (and what to do to make vocabulary an integral part of instruction). In E.H. Hiebert and M.L. Kamil (eds.), Teaching and learning vocabulary: Bringing research to practice. Mahwah, NJ: Erlbaum. 